\title{
Synthesis and Physical Characterization of 4-(anthracen- 10-yl)-1-(4-mthoxyphenyl)-3-phenoxyazetidin-2-one as a New Cis 2-azetidinone
}

\author{
Aliasghar Jarrahpour ${ }^{\text {a,* }}$, Mohammad Nazari ${ }^{\text {a }}$ and Abraham F. Jalbout ${ }^{\text {b }}$ \\ a Department of Chemistry, College of Sciences, Shiraz University, Shiraz 71454, Iran. \\ b Department of Chemistry, University of Arizona, Tucson, AZ 85721 USA \\ *Author to whom correspondence should be addressed . Tel: +98 711 2284822; Fax: +98 711 2280926; \\ E-mail: jarrah@susc.ac.ir
}

Received: 3 January 2007 / Accepted: 19 January 2007 / Published: 31 May 2007

Keywords: $\beta$-Lactam, anthracenyl imine, phenoxy ketene, Staudinger reaction.

\begin{abstract}
The synthesis of 4-(anthracen-10-yl)-1-(4-methoxyphenyl)-3-phenoxy azetidin-2-one is presented here. The AM1 calculations for characterizing the physical properties of the molecule are also given.
\end{abstract}

\section{Introduction}

The $\beta$-lactam antibiotics are comprised of a great variety of semisynthetic penicillins (e.g. amoxicillin (AMOX), ampicillin (AMP), penicillinG (PEN G), oxacillin (OXA), cloxacillin (CLOX)) and cephalosporins (e.g. cephapirin (CEP)). All $\beta$-lactams have at their basic structure a $\beta$-lactam ring responsible for the antibacterial activity and variable side chains that account for the major differences in their chemical and pharmacological properties [1]. The $\beta$-lactamases are the major resistance mechanism in Gram-negative rods, including $P$. aeruginosa [2]. The importance of the stereoselective synthesis of $\beta$-lactams is ever increasing in connection with the structure-activity relationship study and the development of new derivatives of the $\beta$-lactam antibiotics and inhibitors of $\beta$-lactamases [3]. Due to ring strain, azetidine-2-ones are susceptible to ring cleavage reactions. This property has been exploited by several research groups who have utilized the $\beta$-lactam as a synthons for a wide variety of compounds [4]. In this study, some new monocyclic 2-azetidinones bearing an anthracene derivative have been synthesized and one of them is presented here.

\section{Results and Discussion}

Polyaromatic aldimine 1 was prepared in quantitative yield by condensation of 4-methoxybenzenamine and 9-anthraldehyd in refluxing ethanol. The formation of Schiff base $\mathbf{1}$ was readily established from its spectral data. Treatment of $\mathbf{1}$ with ketene derived from phenoxyacetyl chloride in the presence of triethylamine afforded cis-2-azetidinone $\mathbf{2}$ (Scheme 1).

\section{Scheme 1}




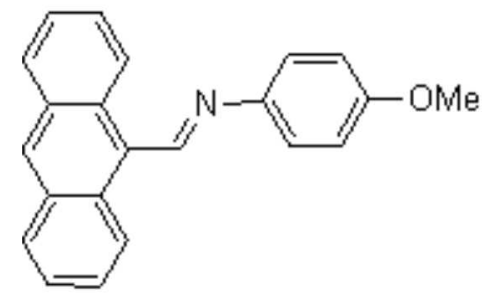

1

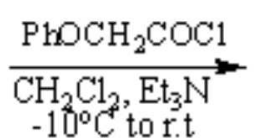

2

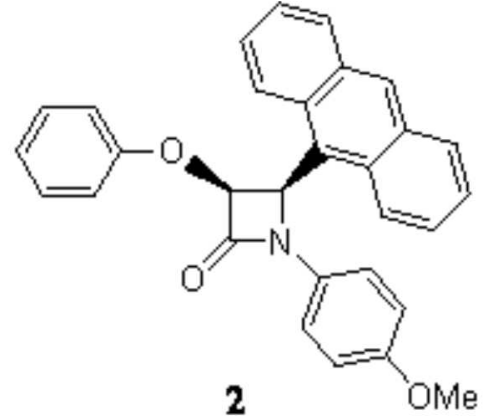

The presence of this new compound was confirmed by t.l.c. monitoring. Its IR spectrum showed the $\beta$-lactam carbonyl at $1773.0 \mathrm{~cm}^{-1}$. The indicated cis stereochemistry for this polycyclic $\beta$-lactam was deduced from analysis of its ${ }^{1} \mathrm{H}-\mathrm{NMR}$ spectrum. The coupling constant of $\mathrm{H}-3$ and $\mathrm{H}-4$ is $J=5 \mathrm{~Hz}$. In addition, ${ }^{13} \mathrm{C}$-NMR spectroscopic data of $\beta$-lactam 2 definitely showed the $\beta$-lactam carbonyl at 165 . The mass spectrum showed the $\mathrm{M}$ and $\mathrm{M}+1$ at 445 and 446 respectively. We next performed theoretical calculations to present a viable structure for the product. All calculations in this work were carried out with the AM1 level of theory using the GAUSSIAN03 suite of programs [5]. More information about these methods is available elsewhere [6]. Figure 1 presents the optimized structure of the molecule with bond lengths and bond angles shown.

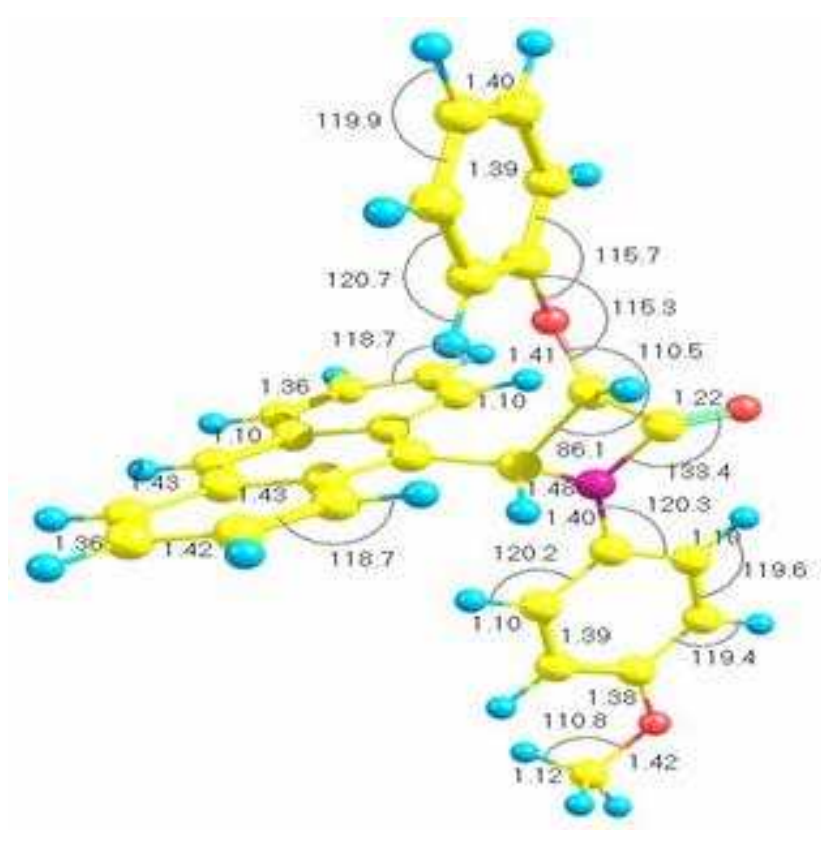

Figure 1. AM1 optimized geometry and with all bond lengths shown in angstroms $(\AA)$, and bond angles in degrees $\left({ }^{\circ}\right)$. ). In the figure, yellow spheres are carbon, blue spheres are hydrogen atoms, purple spheres are nitrogen, green spheres are chlorine and red spheres are oxygen atoms.

Table 1 shows the thermodynamic properties for the structure in figure 1 where $\mathrm{T}$ (temperature in $\mathrm{K}$ ), $\mathrm{S}$ (entropy in $\mathrm{J} \mathrm{mol}^{-1} \mathrm{~K}^{-1}$ ), $\mathrm{C}_{\mathrm{p}}$ (heat capacity at constant pressure in $\mathrm{kJ} \mathrm{mol}^{-1} \mathrm{~K}^{-1}$ ), and $\Delta \mathrm{H}=\mathrm{H}^{\circ}-\mathrm{H}^{\circ} 298.15$ (enthalpy content, in $\mathrm{kJ} \mathrm{mol}^{-1}$ ), $\mathrm{T}_{1}=100 \mathrm{~K}, \mathrm{~T}_{2}=298.15 \mathrm{~K}$, and $\mathrm{T}_{3}=1000 \mathrm{~K}$ calculated $\mathrm{AM} 1$ frequencies. The fits were performed according to the equations implemented by the National Institute of Standards and Technology (NIST) [7].

Table 1. Thermodynamic properties of the molecule in Figure 1, calculated at the AM1 level of theory, where $\mathrm{C}_{\mathrm{p}}$ is the heat capacity in $\mathrm{J} \mathrm{mol}^{-1} \mathrm{~K}^{-1}, \mathrm{~S}$ is the entropy in $\mathrm{J} \mathrm{mol}^{-1} \mathrm{~K}^{-1}$, and $\mathrm{DH}$ is the standard enthalpy $\mathrm{kJ} \mathrm{mol}^{-1}$. These where the fitted results to the Shomate equations [10] which are implemented by the JANAF tables of the NIST databases. These equations converged to an $\mathrm{R}^{2}$ value of 0.999 on average. 
These equations have been very good at predicting physical properties of various molecules, as we have tested in the past [8-10].

\begin{tabular}{l|l|l}
\hline $\mathrm{C}_{\mathrm{p}}$ & $\begin{array}{l}-34.41663+1842.11254 * \mathrm{t}-747.52658 * \mathrm{t}^{2}+2.83512 * \mathrm{t}^{3} \\
+0.37825 * \mathrm{t}^{-2}\end{array}$ \\
\cline { 2 - 3 } $\mathrm{S}$ & $\begin{array}{l}-147.10429 * \ln (\mathrm{t})+2232.95888 * \mathrm{t}-1048.98298 * \mathrm{t}^{2} / 2-15.90654 \\
* \mathrm{t}^{3} / 3-1.6256 /\left(2 * \mathrm{t}^{2}\right)+0.66663\end{array}$ \\
\cline { 2 - 2 } & $\begin{array}{l}13.18293 * \mathrm{t}+129.55004 * \mathrm{t}^{2} / 2+1145.45566 * \mathrm{t}^{3} /-151.20546 * \mathrm{t}^{4} / 4 \\
+0.45831 / \mathrm{t}-0.28471\end{array}$ \\
\hline
\end{tabular}

\section{Experimental}

All required chemicals were purchased from Merck and Fluka chemical companies. Dichloromethane and triethylamine were dried by distillation over $\mathrm{CaH} 2$ and then stored over $4 \AA$ molecular sieves. IR spectra were run on a Shimadzu FT-IR 8300 spectrophotometer. ${ }^{1} \mathrm{H}-\mathrm{NMR}$ and ${ }^{13} \mathrm{C}$-NMR spectra were recorded in $\mathrm{CDCl}_{3}$ (compound 2) using a Bruker Avance DPX instrument (operating at $250 \mathrm{MHz}$ for $1 \mathrm{H}$ and 62.9 $\mathrm{MHz}$ for $13 \mathrm{C}$ ). Chemical shifts were reported in $\mathrm{ppm}(\delta)$ downfield from TMS. All of the coupling constants (J) are in Hertz. The mass spectra were recorded on a Shimadzu GC-MS QP 1000 EX instrument. Elemental analyses were run on a Thermo Finnigan Flash EA-1112 series. Melting points were determined in open capillaries with a Buchi 510 melting point apparatus and are not corrected. Thin-layer chromatography (t.l.c.) was carried out on silica gel 254 analytical sheets obtained from Fluka. Column chromatography was performed on Merck Kieselgel (230-270 mesh).

\section{Synthesis of (E)-N-(antheracen-10-ylmethylene) methoxybenzenamine (1):}

A mixture of 4-methoxybenzenamine $(0.30 \mathrm{~g}, 2.40 \mathrm{mmol})$ and 9 -anthraldehyde $(0.50 \mathrm{~g}, 2.40 \mathrm{mmol})$ was refluxed in ethanol for 2 hours. After cooling the solution the precipitate formed was filtered off and washed with ethanol to give Schiff base 1 as an orange solid and was recrystalized from ethanol (83\%).

M.P. $=165-170{ }^{\circ} \mathrm{C} . \mathrm{IR}\left(\mathrm{KBr}, \mathrm{cm}^{-1}\right): 1637(\mathrm{C}=\mathrm{N}) .{ }^{1} \mathrm{H}-\mathrm{NMR} \delta(\mathrm{ppm}): 3.87(\mathrm{~s}, 3 \mathrm{H}, \mathrm{OMe}), 8.52(\mathrm{~s}, 1 \mathrm{H}$, $\mathrm{C} \underline{H}=\mathrm{N}), 8.69(\mathrm{~d}, 2 \mathrm{H}, \mathrm{Ar}), 8.01$ (d, 2H, Ar), 7.01-7.57 (m, 9H, Ar). ${ }^{13} \mathrm{C}-\mathrm{NMR} \delta(\mathrm{ppm}): 55.59\left(\mathrm{OCH}_{3}\right)$, 114-131 (aromatic carbons), $157.77(\underline{\mathrm{CH}}=\mathrm{N}) . \mathrm{MS}(\mathrm{m} / \mathrm{z}): 310(\mathrm{M}), 311(\mathrm{M}+1), 204,177,134,121,107$, 69.

\section{Synthesis of 4-(anthracen-10-yl)-1-(4-methoxyphenyl)-3-phenoxy-2-azetidinone (2):}

A solution of phenoxyacetyl chloride $(0.22 \mathrm{~g}, 1.30 \mathrm{mmol})$ in dry $\mathrm{CH}_{2} \mathrm{Cl}_{2}(10 \mathrm{~mL})$ was slowly added to a solution of (E)-N-(antheracen-10-ylmethylene) methoxybenzenamine 1 (0.31 g, $1.00 \mathrm{mmol})$ and triethylamine $(0.26 \mathrm{~g}, 2.60 \mathrm{mmol})$ in $\mathrm{CH}_{2} \mathrm{Cl}_{2}(15 \mathrm{~mL})$ at $-10{ }^{\circ} \mathrm{C}$. The reaction mixture was then allowed to warm to room temperature, stirred overnight and then it was washed with saturated sodium bicarbonate solution $(20 \mathrm{~mL})$, brine $(20 \mathrm{~mL})$, dried $\left(\mathrm{Na}_{2} \mathrm{SO}_{4}\right)$ and the solvent was evaporated to give the crude product as a light yellow solid which was then purified by recrystalization from ethyl acetate (Yield 56 $\%)$.

M.P.: $202-205{ }^{\circ} \mathrm{C}$. 
IR $\left(\mathrm{KBr}, \mathrm{cm}^{-1}\right): 1773.0(\beta$-lactam $\mathrm{C}=\mathrm{O}) .{ }^{1} \mathrm{H}-\mathrm{NMR} \delta(\mathrm{ppm}): 3.64(\mathrm{~s}, 3 \mathrm{H}, \mathrm{OMe}), 5.98(\mathrm{H} 3, \mathrm{~d}, 1 \mathrm{H}, \mathrm{J}=5$ $\mathrm{Hz}), 6.57-8.05$ (ArH, m, 18H). ${ }^{13} \mathrm{C}-\mathrm{NMR} \delta(\mathrm{ppm}): 55.30$ (OMe), 59.2 (C4), 83.23 (C3), 114-130 (aromatic carbon), 157.00 (CO), 165.00 (CO, $\beta$-lactam). MS (m/z): $445(\mathrm{M}), 446(\mathrm{M}+1)$, 51, 55, 57, 69, 77, 84, 94, 149, 152, 202, 203, 296, 297, 310, 311. Anal. Calcd for $\mathrm{C}_{30} \mathrm{H}_{23} \mathrm{NO}_{3}: \mathrm{C}, 80.88 ; \mathrm{H}, 5.20$; $\mathrm{N}$, 3.14 Found: C, 80.85; H, 5.22; N, 3.10.

\section{Acknowledgment}

AAJ and MN thank the Shiraz University Research Council for financial support (Grant No.85GR-SC-23). AFJ would like to thank the University of Arizona supercomputer center for these calculations.

\section{References}

1. Yang, J.M.; Cha, S.; Carlson, K.H. J. Chromatogr. A 2006, 1115(1-2), 46-57.

2. Jacoby, G.A.; Munoz-Price L.S. N. Engl. J. Med. 2005, 352, 380-391.

3. Alcaide, B.; Almendros, P.; Pardo, C.; Rodríguez-Vicente, A.; Pilar Ruiz, M. Tetrahedron 2005, 61, 7894-7906.

4. (a) Alcaide, B.; Miranda, M.; Perez-Castelles, J.; Sierra, M.A. J. Org. Chem. 1993, 58, 297-298; (b) Hess, M. Ring Enlargement in Organic Chemistry; VCH Verlagsgesellschaft: D-6940 Weinheim (Federal Republic of Germany); (c) Manhas, M. S.; Wagle, D. R.; Chiang, J.; Bose, A. K. Heterocycles 1988, 27, 1755-1802; (d) Manhas, M. S.; Amin, S. G.; Bose, A. K. Heterocycles 1976, 5, 669-699; (e) Mukherjee, A.K.; Singh, A.K. Synthesis 1975, 547-589; (f) Deshmukh, A.R.A.S.; Bhawal, B.M.; Krishnaswamy, D.; Govande, V.V.; Shinkre, B.A.; Jayanthi, A. Curr. Med. Chem. 2004, 11, 1889-1920; (g) Alcaide, B.; Almendros, B. Curr. Med. Chem. 2004, 11, 1921-1949.

5. Frisch, M. J.; GAUSSIAN03, Revision A.1, M. J. Frisch, Gaussian, Inc., Pittsburgh PA, 2003. 6. Foresman, J.B., Æ Frisch, Exploring Chemistry with Electronic Structure Methods, 2nd edition Gaussian, INC, Pittsburgh, PA, 1996.

7. Linstrom, P.J., Mallard, W.G., Eds., NIST Chemistry WebBook, NIST Standard Reference Database Number 69, July 2001, National Institute of Standards and Technology, Gaithersburg, MD 20899 8. Jalbout, A.F., Solimannejad, M., Labonowski, J.K., Chem. Phys. Letts. 2003, 379, 503.

9. Jalbout, A.F., Jiang, Quasri, A., Jeghnou, H., Rhandour, A. Vib. Spect. 2006, in press. 10. Jalbout, A.F.; Nazara, F.; Turker, L. J. Mol. Struct. (THEOCHEM) 2004, 627, 1. (Invited Review)

(C) 2007 by MDPI (http://www.mdpi.org/). Reproduction is permitted for noncommercial purposes. 